\title{
The treatment of recurrent aortic prosthetic detachment with modified Bentall procedure: Results of two cases
}

\author{
Chong Zhang, MD, Yiming Ni, MD, Liping Shi, MD, and Tao Jin, MD, Hangzhou, China
}

Recurrent prosthetic valve detachment after aortic valve replacement (AVR) for aortic regurgitation is a most serious complication. Endocarditis, aortitis, or other factors are the common causes. AVR or repair of the detachment are usually difficult to manage and still have a high detachment rate. We report 2 cases of successful surgical management with the translocated Bentall procedure for recurrent aortic valve detachment resulting from indefinite causes.

\section{PATIENTS AND METHODS}

Two male patients, 33 and 55 years of age, with severe aortic regurgitation were treated in our institute in 2006 . The clinical and radiologic findings excluded endocarditis and common aortitis. We performed AVR with the CarboMedics mechanical bileaflet prosthesis (Sulzer CarboMedics, Inc, Austin, Tex) and used 15 double-needled interrupted 2-0 synthetic braided pledget-supported sutures, which were left on the ventricular side. The operative and pathologic findings supported the diagnosis of aortic myxomatous degeneration and also further excluded endocarditis and common aortitis. Unfortunately, the valve became detached from the junction between the annulus and aortic wall, but without any evidence of infection. The 2 patients underwent reoperation, one undergoing detachment repair and the other undergoing valve replacement (Table 1). Recurrent prosthetic valve detachment still occurred postoperatively at the same location in these 2 patients without a common cause. Because of the location and frequency of the detachments, the translocated Bentall procedure was performed. In the modified Bentall procedure, the aortic valve prosthesis was sutured into the graft $1 \mathrm{~cm}$ from the end of the graft with a continuous 3-0 polyester suture, forming a composite graft. The composite graft then was implanted into the annulus with everting 2-0 polyester mattress sutures followed by coronary reimplantation and distal anastomosis (Figure 1, A, B, and $C$ ).

\section{RESULTS}

Patient 1 was discharged 14 days later. He remained well with no evidence of valved conduit detachment and had no

From the Department of Thoracic and Cardiovascular Surgery, The First Affiliated Hospital, College of Medicine, Zhejiang University, Hangzhou, China.

Received for publication March 23, 2008; revisions received May 4, 2008; accepted for publication May 20, 2008; available ahead of print Sept 9, 2008.

Address for reprints: Yiming Ni, MD, Department of Thoracic and Cardiovascular Surgery, The First Affiliated Hospital, College of Medicine, Zhejiang University,

Hangzhou 310003, China (E-mail: haiyanzhangchong@163.com).

J Thorac Cardiovasc Surg 2009;138:770-1

$0022-5223 / \$ 36.00$

Copyright (C) 2009 by The American Association for Thoracic Surgery doi:10.1016/j.jtcvs.2008.05.056 reports of symptoms at 1 year's follow-up. Patient 2 had ventricular fibrillation 5 days after the operation, and cardiopulmonary resuscitation was successfully performed. He was discharged on the twentieth day postoperatively and remained well with no evidence of detachment and had no reports of symptoms at 7 months' follow-up (Table 2).

\section{DISCUSSION}

Prosthetic detachment after AVR is one of the most frequent complications necessitating reoperation. ${ }^{1}$ Many common factors, such as endocarditis, aortitis, anatomic characteristics, and surgical management, are thought to predispose to complications. However, endocarditis and common specific aortitis were ruled out in our cases. The intrinsic anatomic factors were also considered. The embryologic origin of partial aortic annular portion could be a reason for its intrinsic weakness. After AVR, some factors could put rigid stress on the weak sector and lead to prosthetic detachment. ${ }^{1,2}$ The aortic leaflets in our patients both exhibited myxomatous degeneration, which manifested as endogenous histologic weakness in the annuloaortic junction. We believe that in AVR, the pressure of valve function directly affects the rigid sewing ring, thereby causing a higher detachment rate.

In accordance with other reports treating Behçet aortitis, ${ }^{3,4}$ we adopted the modified Bentall procedure owing to recurrent detachment without a definite cause. In composite graft reconstruction, the original Bentall operation for this disease was not indicated because of a high risk of suture insufficiency. ${ }^{3}$ The translocated Bentall procedure has often been used in prosthetic detachment caused by aortitis to prevent valve detachment. ${ }^{4}$ Reconstruction with a valved conduit was helpful because the prosthetic valve did not apply direct pressure to the aortic annulus and the flexible tubular prosthesis cushioned the stress. This new modification of the Bentall technique provides better flexibility and elasticity of the aortic annulus than does the standard Bentall procedure. We present our successful treatment experience and possible clinical values for the consideration of clinicians.

TABLE 1. The characteristics of patients and operations

\begin{tabular}{|c|c|c|c|c|c|c|c|c|c|c|}
\hline \multirow[b]{2}{*}{ Patient } & \multirow[b]{2}{*}{ Age } & \multirow[b]{2}{*}{ Gender } & \multicolumn{3}{|c|}{ First operation } & \multicolumn{2}{|c|}{ Aortic prosthesis detachment } & \multicolumn{3}{|c|}{ Second operation } \\
\hline & & & Time & Treatment & Prosthesis & Grade & Location & Time & Treatment & Prosthesis \\
\hline 1 & $33 \mathrm{y}$ & M & May 2006 & AVR & Carobmedics, 23A & Medium & $\mathrm{RCC}$ & Dec 2006 & Repair & No. \\
\hline 2 & $55 \mathrm{y}$ & M & Mar 2006 & AVR & Carobmedics, 25A & $\begin{array}{l}\text { Severe, displacing } \\
\text { into LVOT }\end{array}$ & RCC, partial NCC & June 2007 & AVR & CarboMedics, 25A \\
\hline
\end{tabular}

$\overline{A V R}$, Aortic valve replacement; $R C C$, right coronary cups; $N C C$, noncoronary cups; $L V O T$, left ventricular outflow tract. 

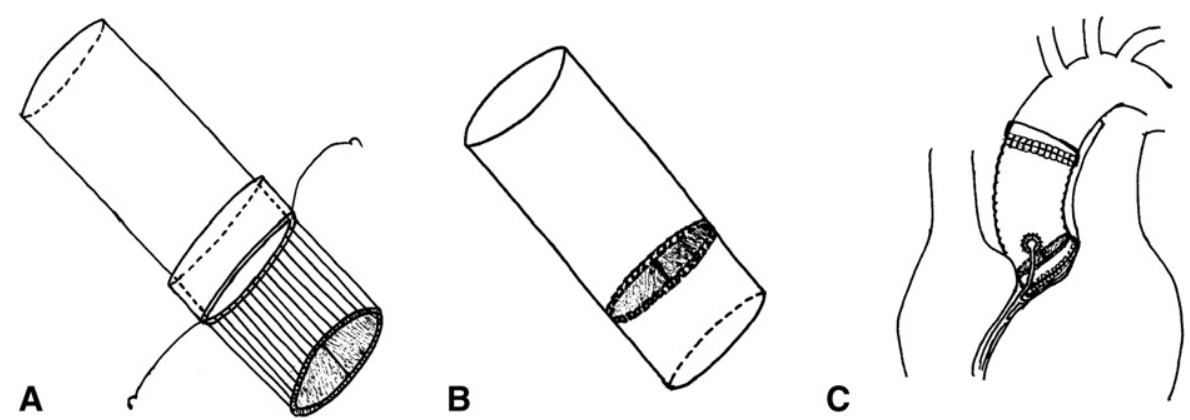

FIGURE 1. The modified Bentall procedure is performed through the following main steps, which are slightly different from those of a standard Bentall operation. A, First, the proximal end of the vascular graft is everted outward and upward for about $1 \mathrm{~cm}$. A mechanical prosthesis is sutured to the free margin of the everted graft with a continuous 3-0 polyester suture to fix the bottom border of prosthesis to the graft. B, Once the anastomosis is completed, the homemade composite conduit is everted and returned to its original position. The composite graft is ready for aortic root replacement. C, The proximal anastomosis is performed with everting 2-0 polyester mattress sutures between the aortic annulus and the proximal free edge. Then the coronary reimplantation and distal anastomosis are performed.

TABLE 2. Clinical details, outcomes, and follow-up of patients with modified Bentall procedure

\begin{tabular}{llllccccc}
\hline Patient & Detachment location & Time & Procedure & Complications & Outcome & Follow up & Echocardiography \\
\hline 1 & RCC, partial NCC & Feb 2007 & CarboMedics, 23A valved conduit & No & Discharged & Alive & Good \\
2 & RCC, partial NCC & Aug 2007 & CarboMedics, 25A valved conduit & VF & Discharged & Alive & Good \\
\hline
\end{tabular}

$R C C$, Right coronary cups; $N C C$, noncoronary cups; $V F$, ventricular fibrillation.

Nevertheless, further investigation is required because of the small cohort of patients and the short follow-up time.

\section{References}

1. De Cicco G, Lorusso R, Colli A, Nicolini F, Fragnito C, Grimaldi T, et al. Aortic valve periprosthetic leakage: anatomic observations and surgical results. Ann Thorac Surg. 2005;79:1480-5.
2. Lansac E, Lim KH, Shomura Y. Dynamic balance of the aortomitral junction. $J$ Thorac Cardiovasc Surg. 2002;123:911-7.

3. Ando M, Kosakai Y, Okita Y, Nakano K, Kitamura S. Surgical treatment of Behçet's disease involving aortic regurgitation. Ann Thorac Surg. 1999;68: 2136-40.

4. Okada K, Eishi K, Takamoto S, Ando M, Kosakai Y, Nakano K, et al. Surgical management of Behçet's aortitis: a report of eight patients. Ann Thorac Surg. 1997;64:116-9.

\title{
Successful emergency surgery for coexistent acute aortic syndrome and acute carotid artery obstruction
}

\author{
Masahiko Ando, MD, Kazuhito Imanaka, MD, Hideaki Yamabi, MD, and Hiroshige Sato, MD, Saitama, \\ Japan
}

Few surgeons advocate surgical intervention for patients with acute aortic syndrome and coma, especially on an emergency basis, because of very poor outcome. ${ }^{1}$ We herein

\footnotetext{
From the Department of Cardiovascular Surgery, Saitama Medical Center, Saitama, Japan.

Received for publication May 11, 2008; revisions received May 11, 2008; accepted for publication May 26, 2008; available ahead of print Sept 22, 2008.

Address for reprints: Masahiko Ando, MD, 1981 Tsujido-machi, Kamoda, Kawagoeshi, Saitama 350-8550, Japan (E-mail: masandoo@hotmail.com).

J Thorac Cardiovasc Surg 2009;138:771-3

$0022-5223 / \$ 36.00$

Copyright (C) 2009 by The American Association for Thoracic Surgery

doi:10.1016/j.jtcvs.2008.05.063
}

describe an emergency operation for a comatose and hemiplegic octogenarian in a state of profound shock caused by rupture of a penetrating aortic ulcer (PAU) in the ascending aorta. Duplex scanning disclosed a slightly mobile thrombus nearly impacting into the right internal carotid artery. This patient successfully underwent replacement of the ascending aorta and right carotid endarterectomy concomitantly. Removal of this thrombus appeared to be highly beneficial. Preoperative evaluation of the carotid arteries has priority in patients with acute aortic syndrome and some neurologic deficits. 